\author{
Hill and Upland Livestock Production \\ Occasional Publication No. 10-British Society of Animal Production 1985 \\ edited by T. J. Maxwell and R. G. Gunn
}

\title{
SILAGE FOR LAMB FINISHING
}

\section{GILLIAN BUTLER}

ADAS, Government Buildings, Kenton Bar, Newcastle-upon-Tyne

$\mathbf{L}$ amb finishing on silage-based diets is a relatively new technique. It offers an alternative to forage crops without the rigid commitment to a quick finish on intensive, all concentrate lamb feeding.

The poster reported some of the findings from ADAS trial work, carried out on Experimental Husbandry Farms (EHF) and on commercial farms. It gave guidelines for silage quality for lamb finishing and suggestions for the type and level of supplements to use.

The overall impression from the many trials carried out is that success depends on silage intake by the lambs. Maximizing silage intake reduces the need for supplementation.

As with other livestock, silage intake by lambs depends on a number of features of the silage. It is not easy to differentiate the effect on intake of each one but those with a major bearing on intake were found to be:

i. Dry matter level-intake is reduced if silage is wet, less than about $22 \%$ DM.

ii. Fermentation - lambs will eat less of a silage if it is either very acid ( $<\mathrm{pH} \mathrm{4.0)}$ ) or poorly preserved (an ammonia nitrogen level of more than $10 \%$ of total nitrogen).

iii. D value - intake is lower on low $D$ value silages.

iv. Chop length - long silage (big bale) has a lower intake than comparable precision chopped silage.
The type and level of supplement also influences silage intake. Barley-based concentrates tended to depress silage intake whereas, in most cases, a small amount of fish meal (or protected soya bean meal) increased the lambs' silage intake.

In one trial at Liscombe EHF, silage intake (and lamb performance) was shown to be improved by clipping the lambs at housing.

The type and level of supplement needed not only depends on silage intake but also on the expected level of performance by the lambs. Early in the season they may be expected to grow relatively slowly at $50-60 \mathrm{~g} /$ day and need less supplementation than later, when they are 'finishing' with a daily live-weight gain (DLWG) of up to $150 \mathrm{~g}$.

A range of supplements has been investigated in various combinations and comparisons, namely nothing, whole and rolled barley, whole and rolled oats, barley plus fish meal, barley plus soya bean meal, barley plus protected soya bean meal, molasses, fish meal, protected soya bean meal and purchased "concentrates". Results (like the silages) have been variable. Two relevant comments might bc:

i. Silage quality has more influence over lamb performance than the type of supplement or the level of feeding.

\section{Suggested concentrates to supplement silage for lambs (daily allowances)}

Silage $D$ value

$66+$

65

64

63

62

61

$<60$
'Holding' store lambs

(50 g DLWG)

None

None

$30 \mathrm{~g}$ Fish meal

$30 \mathrm{~g}$ Fish meal

$250 \mathrm{~g}$ Barley + fish meal or barley + soya bean meal (15\% CP)

$350 \mathrm{~g}$ Barley + fish meal or barley + soya bean meal ( $15 \% \mathrm{CP})$

$450 \mathrm{~g}$ Barley + fish meal or barley + soya bean meal ( $15 \% \mathrm{CP})$
Finishing lambs

$(150 \mathrm{~g}$ DLWG)

$30-50 \mathrm{~g}$ Fish mcal

$250 \mathrm{~g}$ Barley + fish meal or barley + soya bean meal (15\% CP)

$350 \mathrm{~g}$ Barley + fish meal or barley + soya bean meal (15\% CP)

$450 \mathrm{~g}$ Barley + fish meal or barley + soya bean meal ( $15 \% \mathrm{CP})$

60) $g$ Barley + fish meal or barley + soya bean meal (15\% CP)

$750 \mathrm{~g}$ Barley + fish meal or barley + soya bean meal (15\% CP)

$900 \mathrm{~g}$ Barley + fish meal or barley + soya bean meal $(15 \% \mathrm{CP})$ 
ii. An energy source (cereal or molasses) does not appear to be the ideal supplement for lambs on silage.

In view of the results, initial advice to anybody contemplating finishing lambs on silage would be to make quality silage. Suggested targets would be: a dry matter of at least $25 \%$, an ammonia nitrogen level of less than $10 \%$ of the total nitrogen, a D value of at least $65 \%$ and a relatively short chop length, $25-50 \mathrm{~mm}$.

If this cannot be achieved, the above table gives guidelines to the necessary level of supplements. The figures given in the table are for silage which is chopped, well fermented and reasonably dry. If the silage to be used is long (big bale), wet or has undergone a butyric fermentation, the supplement will need to be increased (moving 2-3 rows down the table). 